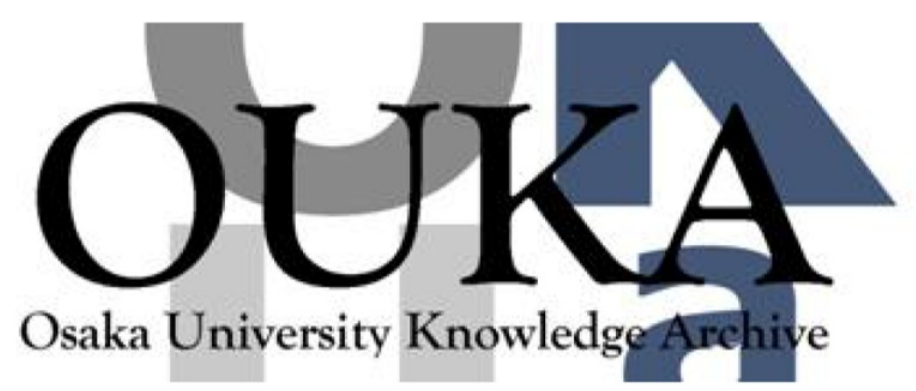

\begin{tabular}{|c|c|}
\hline Title & $\begin{array}{l}\text { Inspection of stress corrosion cracking in } \\
\text { welded stainless steel pipe using point- } \\
\text { focusing electromagnetic-acoustic transducer }\end{array}$ \\
\hline Author (s) & $\begin{array}{l}\text { Nakamura, Nobutomo; Ashida, Kazuhiro; } \\
\text { Takishita, Takashi et al. }\end{array}$ \\
\hline Citation & NDT \& E International. 83 p. 88-p. 93 \\
\hline Issue Date & $2016-10$ \\
\hline oaire:version & AM \\
\hline URL & https://hdl. handle. net/11094/84478 \\
\hline rights & $\begin{array}{l}\text { ( } 2016 \text { Elsevier Ltd. This manuscript version is } \\
\text { made avai lable under the Creative Commons } \\
\text { Attribut ion-NonCommercial-NoDerivatives } 4.0 \\
\text { International License. }\end{array}$ \\
\hline Note & \\
\hline
\end{tabular}

Osaka University Knowledge Archive : OUKA

https://ir. Library. osaka-u. ac. jp/

Osaka University 


\title{
Inspection of stress corrosion cracking in welded stainless steel pipe using point-focusing electromagnetic-acoustic transducer
}

Nobutomo Nakamura*, Kazuhiro Ashida, Takashi Takishita, Hirotsugu Ogi, Masahiko Hirao

Graduate School of Engineering Science, Osaka University, 1-3 Machikaneyama, Toyonaka, Osaka 560-8531, Japan

\begin{abstract}
Point-focusing electromagnetic-acoustic transducers (PF-EMATs) for shearvertical (SV) waves were developed for crack inspection of stainless-steel pipes. The transducer has improved defect detectability by accumulating SV waves generated by concentric line sources at a focal point in phase. An optimum frequency for defect detection was found to be $2 \mathrm{MHz}$, with which a crack of 0.5-mm depth near a weld was clearly detected. The EMAT exhibited defect detectability comparable to that of a conventional phased-array piezoelectric transducer, indicating that this new EMAT is highly practical for the non-contacting evaluation of stress-corrosion cracking in stainless steels.
\end{abstract}

Keywords: Electromagnetic acoustic transducer, point focusing, SV wave, weld, stress corrosion cracking

\footnotetext{
*Corresponding author

Email address: nobutomo@me.es.osaka-u.ac.jp (Nobutomo Nakamura) 


\section{Introduction}

Stress-corrosion cracking (SCC) around welds is the critical failure of stainless-steel pipes in chemical and power plants, and nucleation and growth of cracks are routinely inspected by the ultrasonic testing (UT). Crack size is normally estimated from amplitude of ultrasonic waves (echoes) reflected by the cracks. For monitoring crack growth with this method, however, reproducibility of the amplitude measurement must be guaranteed. High signal-to-noise $(\mathrm{S} / \mathrm{N})$ ratio is also required to detect small cracks in the early stage.

With piezoelectric transducers, echo amplitude is highly affected by the measurement conditions such as surface roughness of specimens and contacting pressure between a specimen and transducers. These features lower the reproducibility of the amplitude measurement, making inspection of degradation over time unreliable. In addition, a requirement of coupling materials restricts an inspection with moving transducers by robots. In contrast, an electromagnetic acoustic transducer (EMAT) $(1 ; 2 ; 3 ; 4)$ allows the noncontact operation, being free from coupling materials. Ultrasonic-wave sources are generated directly in inspected materials, and echo amplitude is not affected by the contacting pressure. It is also insensitive to the surface roughness. These are advantages over the piezoelectric transducers, and there are studies using EMATs for several industrial purposes, $(5 ; 6 ; 7 ; 8 ; 9 ; 10)$ in addition to the crack inspection. $(11 ; 12)$

The $\mathrm{S} / \mathrm{N}$ ratio of an EMAT is generally smaller than that of a piezoelectric transducer. However, it has been overcome by increasing strain energy density using the focusing $(13 ; 14 ; 15)$ and the resonant $(16)$ techniques, by 
which weak elastic waves are superimposed in phase to produce a high enough intensity. In this study, we design an advanced EMAT utilizing the former technique for crack inspection of stainless-steel pipes. By focusing shear vertical (SV) waves generated from several circular line sources of an EMAT at a focal point, the $\mathrm{S} / \mathrm{N}$ ratio and spatial resolution are improved, making detection of small cracks possible. We developed a SV-wave point-focusing EMAT (PF-EMAT), and confirmed its ability for detecting slit defects deeper than $0.05 \mathrm{~mm} .(17 ; 18)$ As the operating frequency increases, smaller cracks will be detected, although attenuation due to scattering by grains becomes significant. Thus, an optimum driving frequency should exist for the crack inspection with the PF-EMAT. In this study, we developed PF-EMATs operating at different frequencies between 1.1 and $3.0 \mathrm{MHz}$, and evaluated their defect detectability and spatial resolution for stainless steels. Then, cracks artificially fabricated near a weld in a stainless-steel pipe were inspected, and applicability of the developed PF-EMAT for crack inspection was discussed.

\section{Experiments}

\subsection{PF-EMAT}

The developed EMAT consists of two identical concentric meander-line coils and magnets as shown in Fig. 1(a). Hand-wound coils are placed on a specimen surface, and rectangular parallelepiped magnets oppositely polarized are placed on them. The EMAT is operated by inputting burst currents into one of the coils. The currents generate eddy currents on the specimen surface, and the Lorentz forces are generated parallel to the specimen surface and normal to the coil, which are sound sources of SV waves. The SV waves 
generated on the specimen surface are reflected by cracks on the bottom surface, and the reflected waves are detected by the other coil.

An SV wave radiated from a narrow line source vibrating parallel to a specimen surface and perpendicular to the line source shows unique directivity. Amplitude and phase vary depending on the radiation angle, $\theta$, from the normal direction to the specimen surface.(19) In a stainless-steel specimen, amplitude is nearly constant from $0^{\circ}$ to $30^{\circ}$, shows a peak around $32^{\circ}$, drops to zero at $45^{\circ}$, and becomes less than $13 \%$ of the maximum above $45^{\circ}$.(18) The phase is unchanged between 0 and $32^{\circ}$, and it varies above $32^{\circ}$.

Point focusing is performed by using interference of SV waves generated by a meander-line coil. Current direction in the meander-line coil is alternative between the neighboring segments, and phases of SV waves radiated from the segments are different by $\pi$, half cycle. When the SV waves radiated from each segment arrive at a focal point in phase, the amplitude is enhanced and the point focusing is performed. Spacing between the segments is determined so that difference in the length of the propagation paths from the neighboring sources to the focal point equals the half of the wavelength $\lambda$, $R_{i+1}-R_{i}=\lambda / 2$, where $R_{i}$ is the distance between the focal point and $i$ th segment (Fig. 1(a)). We designed EMATs with the radiation angles less than $37.5^{\circ}$ so as to neglect the angle dependence of the phase. The shear-wave velocity of stainless steel was set to be $3100 \mathrm{~m} / \mathrm{s}$.

We used plate specimens with 20-mm thickness and a pipe specimen with 35-mm thickness as described later. We fabricated five PF-EMATs operated at $1.1,1.5,2.0,2.5$, and $3.0 \mathrm{MHz}$ for the plate specimens. The cycles of the driving burst signal were 4 at $1.1 \mathrm{MHz}, 8$ at $1.5 \mathrm{MHz}$, and 12 at other 
frequencies, so that the driving signal did not overlap the signal of SV waves reflected by cracks. Amplitude of the received signal was determined by gating out the intended signal and using a superheterodyne technique. The number of segments were $4,5,7,8$, and 10 in 1.1, 1.5, 2.0, 2.5, and 3.0 $\mathrm{MHz}$ EMATs, respectively. Size of the coils was about $15 \mathrm{~mm}$ by $15 \mathrm{~mm}$. Focal points of the EMATs were set to be on the bottom surface of the specimens with 20-mm thickness; the depth of the focal point corresponded to the thickness of the specimens. For the pipe inspection, we designed a 2-MHz PF-EMAT whose focal depth was $35 \mathrm{~mm}$. The number of cycles of the driving burst signal was set to be 20 , and the number of segments was 10.

\subsection{Specimens}

Notches with rectangular cross section were fabricated by an electric discharge machine on back surfaces of stainless steel (SUS304) plates with thickness of $20 \mathrm{~mm}$. The notch width and length were $0.5 \mathrm{~mm}$ and $10 \mathrm{~mm}$, respectively, and the depth, $d$, ranged from 0.05 to $2.95 \mathrm{~mm}$. A welded stainlesssteel specimen was also prepared. The specimen, a curved plate, including welded region was cut from a stainless steel (SUS316) welded pipe, and stress corrosion cracks were introduced beside the weld metal on the inner surface by applying bending stress in a corrosion solution. Outer diameter and thickness around the welded region were 600 and $35 \mathrm{~mm}$, respectively. Excess weld metal on the outer surface was removed. In the following discussion, $x$ and $y$ axes were defined parallel to and normal to, respectively, the notch for the plate specimen and the weld line for the pipe specimen (Fig. 1(b)). 


\section{Results and discussion}

\subsection{Frequency dependences of notch detectability and spatial resolution}

Figure 2 shows representative waveforms averaged over 16 shots obtained by using the 2 and 3-MHz PF-EMATs from a flawless region and from the notch of $0.8-\mathrm{mm}$ depth. In the waveform at $3 \mathrm{MHz}$ from a flawless region, a signal is observed at the gate position; a similar signal is observed also for 2.5-MHz PF-EMAT. Its amplitude is almost unchanged when the EMATs are moved in flawless regions, and the signal is expected to originate from acoustic waves that are reflected at the bottom surface (the origin is not completely understood yet). The signal overlaps with echoes from notches, but the notches are detectable by measuring relative changes in the amplitude. In the following amplitude profiles shown in Figs. 3, 4, and 5, the background amplitude is subtracted from the measured amplitude, and relative change in the amplitude is plotted. Figure 3 shows the notch-depth dependence of the echo amplitude when the focal point was set to the notches. As the notch depth increased, the amplitude first increased monotonically and showed oscillation behaviors. The amplitudes from the notches of $d=0.05$ and $0.15 \mathrm{~mm}$ increased as the operating frequency increased, indicating that higher frequencies were sensitive to shallower notches. On the other hand, the oscillation period became shorter as the frequency increased, and the maximum notch depth below which the amplitude increased monotonically became smaller. This indicates that sizing for larger cracks will be difficult by the PF-EMATs operated at higher frequencies, showing the narrower dynamic range. Interference of SV waves scattered at the tip and the opening of the notches explains the oscillation behavior. We consider propagation of 
a representative SV wave transmitted and received by an EMAT. Its radiation angle is assumed to be $20^{\circ}$, which is the average of radiation angles of $\mathrm{SV}$ waves. When the SV wave is scattered at the tip and opening, difference of their round-trip propagation distances is given by $\Delta l=2 d \cos \theta$. When $\Delta l=(2 n+1) \lambda, n=0,1, \ldots$, interference diminishes the received waves. According to this calculation, the periodicity of the oscillation in the amplitude is $0.86 \mathrm{~mm}$ at $2 \mathrm{MHz}$ and $1.57 \mathrm{~mm}$ at $3 \mathrm{MHz}$. These values correspond to the periodicities observed in Fig. 3.

Figure 4 shows amplitude profiles measured by moving the EMATs in the $x$ direction. With the EMATs operated at 2 and $3 \mathrm{MHz}$, the shallowest notch, $d=0.05 \mathrm{~mm}$, was identified clearly; the amplitude increased as the focal point approached the defect, showed a plateau on the defect, and decreased after the edge. Slopes at the edges were comparable, and the resolutions were deduced to be $4 \mathrm{~mm}$ along the notches. At $1.1 \mathrm{MHz}$, the $0.05-\mathrm{mm}$ notch was not detectable, and the plateau did not appear for the 0.80 -mm notch, indicating lower spatial resolution than others.

Figure 5 shows amplitude profiles measured by moving the EMATs in the $y$ direction. At 1.1 and $2 \mathrm{MHz}$, the profiles showed a peak around the notch, and it was broader at $1.1 \mathrm{MHz}$, indicating lower spatial resolution of the $1.1-\mathrm{MHz}$ EMAT than others in the $y$ direction as well as the $x$ direction. At $3 \mathrm{MHz}$, spikes were observed, and a single peak did not appear. At notches, SV waves are scattered at the tip and the opening, and it causes complicated interferences. As the operating frequency becomes higher, stress field around a defect should become complicated, causing spikes in the profile. Thus, above $2 \mathrm{MHz}$, notable improvement of the spatial resolution was 
not observed. From these results, we conclude that the PF-EMAT operated at $2 \mathrm{MHz}$ possesses appropriate spatial resolutions, dynamic range, and detectability of shallow defects.

\subsection{Imaging of cracks near a weld of a pipe}

For inspection of the welded pipe specimen, we developed another $2-\mathrm{MHz}$ coil. (Note that the number of the line segment can be increased to be 10 in this case because of the thicker specimen.) Penetrant testing (PT) and UT with a phased-array piezoelectric transducer using SV waves at $3 \mathrm{MHz}$ were performed for comparison. The results are shown in Figs. 6(a) and 6(b), respectively. Figure 6(c) shows the echo-amplitude distribution measured by moving the 2-MHz PF-EMAT around the weld metal by the pitch of $1 \mathrm{~mm}$. (A linear interpolation was performed on the figure.) After the inspection, the specimen was cut along the dashed lines indicated in the Fig. 6(c), and the pieces were etched using aqua regia. Cross sectional observations with a microscope were then performed to determine the depth and shape of the cracks, as shown in Fig. 7. The depths are listed in Table I.

In the PT image, four cracks were indicated near the weld metal; Cracks 1 and 2 were located at about $8 \mathrm{~mm}$ from the weld metal on the bottom surface, and Cracks 3 and 4 were located beside it. All of the cracks were detected by both the phased-array transducer and the PF-EMAT. However, the echo amplitude showed different trends. Cracks 1, 2, and 3 grew normal to the specimen surface. Among them, Crack 3 was deeper than others, and intense echoes were observed around it in the phased-array image. However, the echo amplitude was not so large in the PF-EMAT image. Oppositely, the echo amplitude measured by the PF-EMAT for Crack 1 was large comparing 
to that measured by the phased-array transducer. Amplitude around Crack 2 , the shallowest crack, showed intermediate values for both transducers. Regarding Crack 4, wide distribution of high-amplitude area was observed in the PF-EMAT image. From the cross sectional observation along line C, branching of Crack 4 was observed, and the PF-EMAT successfully reproduced it. However, in the phased-array image, the broadening was not observed. Thus, both transducers could detect cracks, but the echo amplitude did not necessarily increase monotonically with increasing crack depth. This is attributed to the oscillation behaviors observed in Fig. 3. Because the phased-array transducer uses the focusing technique, an oscillation should occur as well, though the period is different due to the difference in the operation frequency. Resolution in the $x$ direction is apparently higher in the PF-EAMT image; variations of amplitude in cracks are visible. This is the advantage of the point-focusing; the in-plane focusing was not performed in the phased-array transducer.

From these results, we consider that the crack detectability of the PFEMAT is comparable to that of the phased-array transducer. Sizing of cracks that are deeper than a threshold depth, where the first peak appears in the amplitude-oscillation behavior in Fig. 3, is difficult for both transducers.

\section{Conclusions}

We designed the point-focusing electromagnetic acoustic transducers utilizing the point focusing technique and interference of SV waves, and evaluated the defect detectability at different operating frequencies. Monotonical increase of the echo height with depth was observed for all EMATs, and 
notch-defect detectability was improved as the operating frequency increased, although the dynamic range was decreased. Spatial resolution was improved with increasing the operating frequency. Finally, we found that the $2-\mathrm{MHz}$ PF-EMAT was suitable for inspection of stainless steel plates. A welded stainless steel pipe was inspected, and it was demonstrated that cracks near the weld metal were detectable and scanning measurements were possible using the developed EMAT.

\section{Acknowledgements}

Authors thank Y. Kamiyama and T. Furukawa, The Japan Power Engineering and Inspection Corporation (JAPEIC), for supplying the weld specimen and the data of the PT and UT with the phased-array transducer. This work was supported by JSPS KAKENHI Grant Number 15K13834. 


\section{References}

[1] Wallace WD. Electromagnetic generation of ultrasound in metals. Int J Nondestr Test 1971;2:309-334.

[2] Moran TJ, Panos RM. Electromagnetic generation of electronically steered ultrasnoic bulk waves. J Appl Phys 1976;47:2225-2227.

[3] Thompson RB. A model for the electromagnetic generation of ultrasonic guided waves in ferromagnetic metal polycrystals. IEEE Trans Sonics Ultrason 1978;25:7-15.

[4] Maxfield BW, Fortunko CM. The design and use of electromagnetic acoustic wave transducers (EMATs). Mater Eval 1983;41:1399-1408.

[5] Clark Jr AV, Moulder JC. Residual stress dtermination in aluminum using electromagnetic acoustic transducers. Ultrasonics 1985;23:7-16.

[6] Kawashima K, Wright OB. Resonant electromagnetic excitation and detection of ultrasonic waves in thin sheets. J Appl Phys 1992;72:48304839.

[7] Ogi H, Takashima K, Ledbetter H, Dunn ML, Shimoike G, Hirao M, Bowen P. Elastic constants and internal friction of an SiC-fiberreinforced Ti-alloy-matrix crossply composite: measurement and theory. Acta Mater 1999;47:2787-2796.

[8] Hirao M, Ogi H, Yasui H. Contactless measurement of bolt axial stress using a shear-wave electromagnetic acoustic transducer. NDT E Int 2001;34:179-183. 
[9] Nurmalia, Nakamura N, Ogi H, Hirao M. Mode conversion and total reflection of torsional waves for pipe inspection. Jpn J Appl Phys 2013;52:07HC14.

[10] Nagy PB, Simonetti F, Instanes G. Corrosion and erosion monitoring in plates and pipes using constant group velocity Lamb wave inspection. Ultrasonics 2014;54:1832-1841.

[11] Dewhurst RJ, Edwards C, Palmer SB. Noncontact detection of surfacebreaking cracks using a laser acoustic source and an electromagnetic acoustic receiver. Appl Phys Lett 1986;49:374-376.

[12] Hill S, Dixon S. Localization of defects with time and frequency measuring using pulsed arrays. NDT E Int 2014;67:24-30.

[13] Alers GA, MacLauchlan DT. High Frequency, angle beam EMATs for weld inspection. Review of Progress in Quantitative Nondestructive Evaluation 1983;2A:271-281.

[14] Ogi H, Hirao M, Ohtani T. Line-focusing of ultrasonic SV wave by electromagnetic acoustic transducer. J Acoust Soc Am 1998;103:2411-2415.

[15] Ogi H, Hirao M, Ohtani T. Line-focusing electromagnetic acoustic transducers for detection of slit defects. IEEE Trans Ultrason Ferroele Freq Cont 1999;46:341-346.

[16] Hirao M, Ogi H, Fukuoka H. Resonance EMAT system for acoustoelastic stress measurement in sheet metals. Rev. Sci. Instrum. 1993;64:31983205. 
[17] Takishita T, Ashida K, Nakamura N, Ogi H, Hirao M. Development of shear-vertical-wave point-focusing electromagnetic acoustic transducer. Procc Sym Ultrason Electron 2014;35:9-10.

[18] Takishita T, Ashida K, Nakamura N, Ogi H, Hirao M. Development of shear-vertical-wave point-focusing electromagnetic acoustic transducer. Jpn J Appl Phys 2015;54:07HC04.

[19] Miller GF, Pursey H. The field and radiation impedance of mechanical radiators on the free surface of a semi-infinite isotropic solid. P Roy Soc Lond A Mat 1954;223:521-541. 


\section{Figure Captions}

FIG. 1 (a) Configuration of the PF-EMAT, and (b) the coordinate system in the specimen.

FIG. 2 Representative waveforms obtained by the 2 and 3-MHz PF-EMATs from a flawless region and a notch with $0.8-\mathrm{mm}$ depth. The arrows indicate the gate positions.

FIG. 3 Notch depth and amplitude of reflected waves from notches measured by the PF-EMATs operated at different frequencies.

FIG. 4 Amplitude profiles along the notches. The notches are located between the dashed lines. The notch depths are (a) 0.05 and (b) 0.80 $\mathrm{mm}$.

FIG. 5 Amplitude profiles in the normal direction to the notch. The notch is located at $0 \mathrm{~mm}$, indicated by the dashed line. The notch depth is $0.80 \mathrm{~mm}$.

FIG. 6 Results of (a) the penetrant testing, (b) ultrasonic testing using the phased-array piezoelectric transducer, and (c) ultrasonic testing using the PF-EAMT.

FIG. 7 Cross-sectional images of the welded pipe specimen. (A)-(D) denote the lines shown in Fig. 6. Crack 4 indicated by the asterisk in (B) is supposed to be a part of the Crack 4. Inset of $(D)$ is the enlarged image around Crack 2. 
Table 1: Crack depth (mm) measured by cross-sectional observations.

\begin{tabular}{c|cccc}
\hline \hline & Line A & Line B & Line C & Line D \\
\hline Crack 1 & $1.8-2.3$ & $1.3-1.6$ & - & - \\
Crack 2 & - & - & - & $0.5-0.6$ \\
Crack 3 & $2.5-2.6$ & - & - & - \\
Crack 4 & - & $1.9-2.4$ & $4.6-4.9$ & - \\
$*$ Crack 4 & - & 5.0 & - & - \\
\hline \hline
\end{tabular}




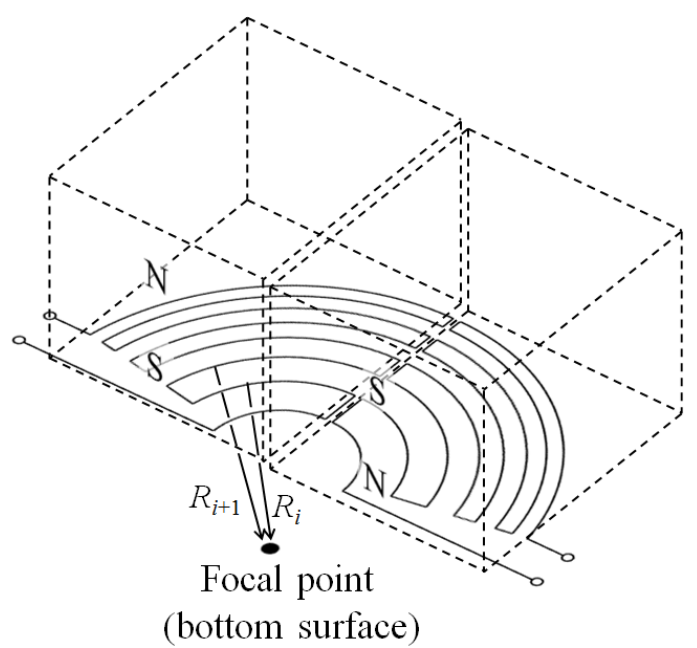

(a)

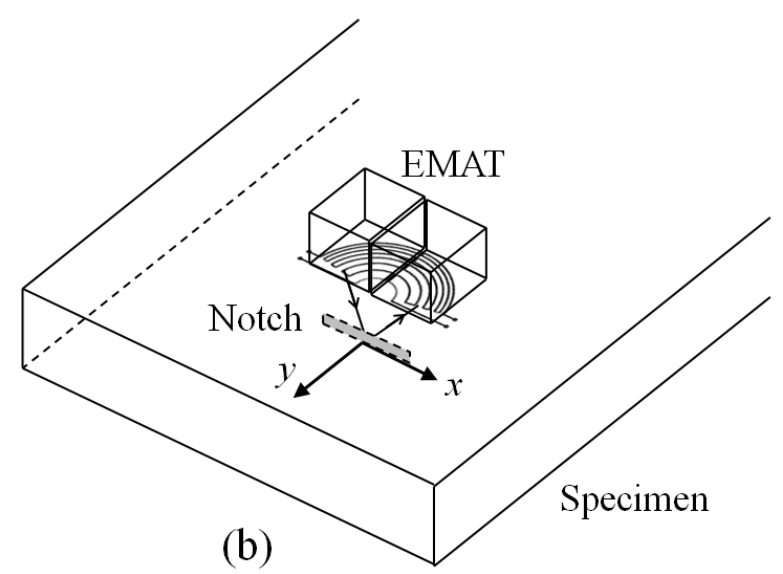

Figure 1: 

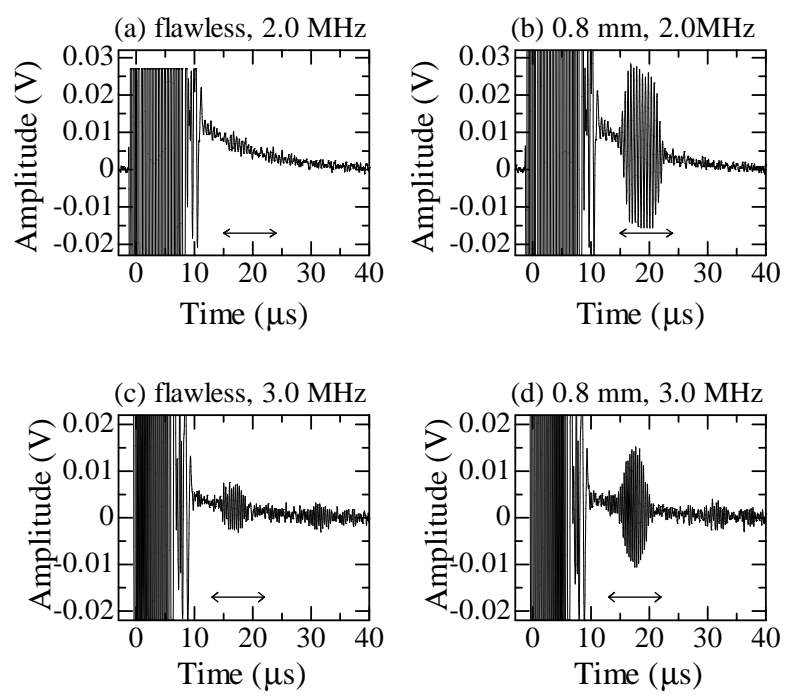

Figure 2: 


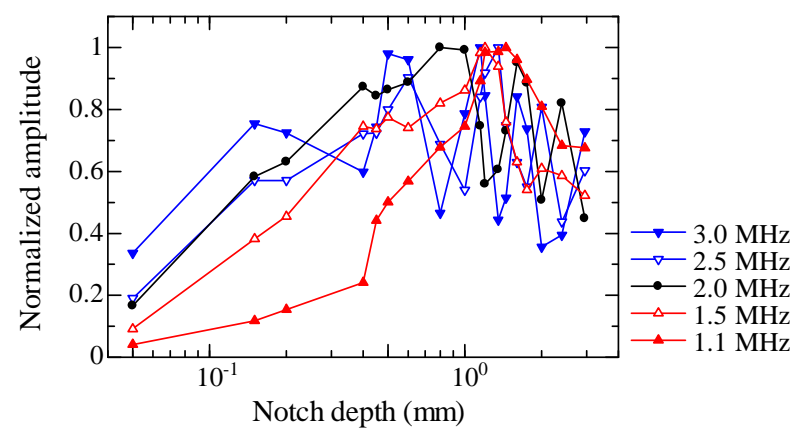

Figure 3: 

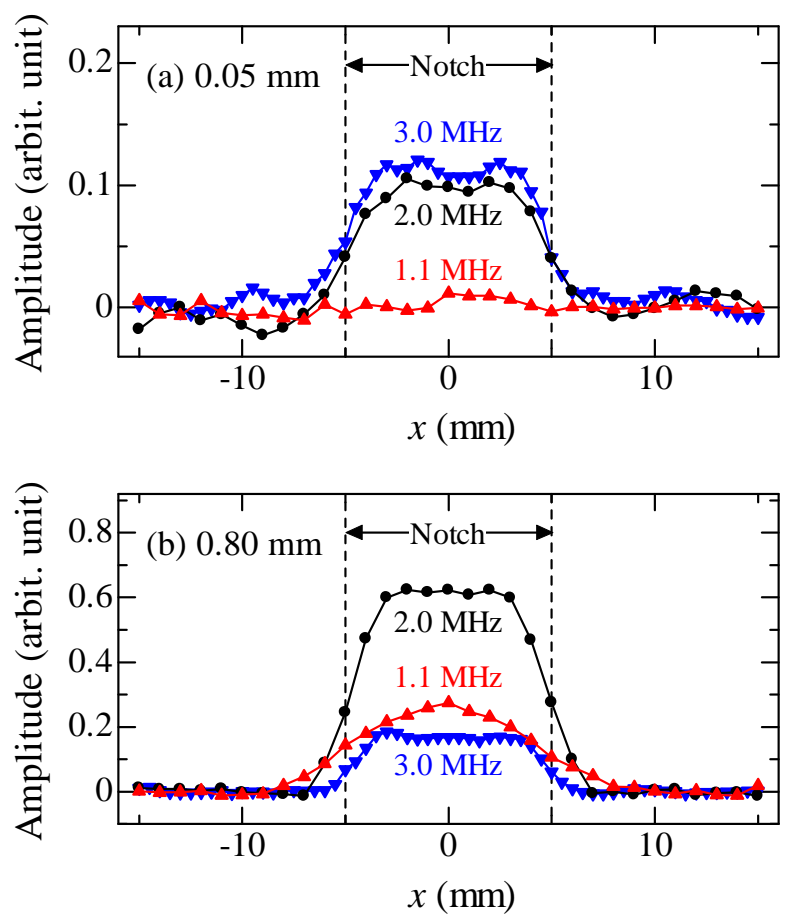

Figure 4: 


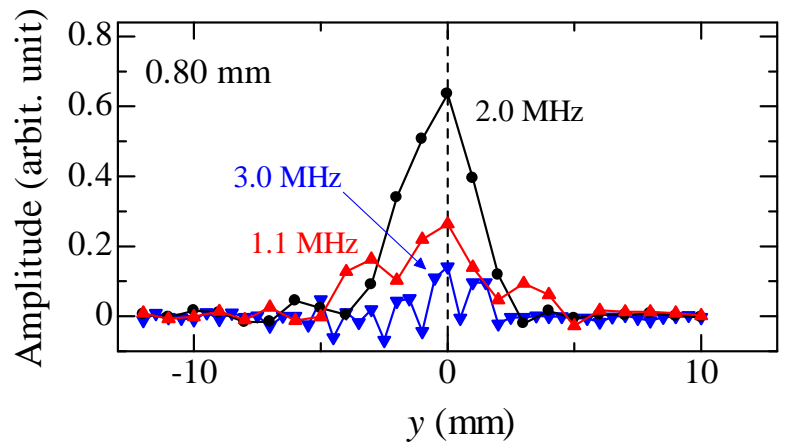

Figure 5: 
(a) $\mathrm{PT}$

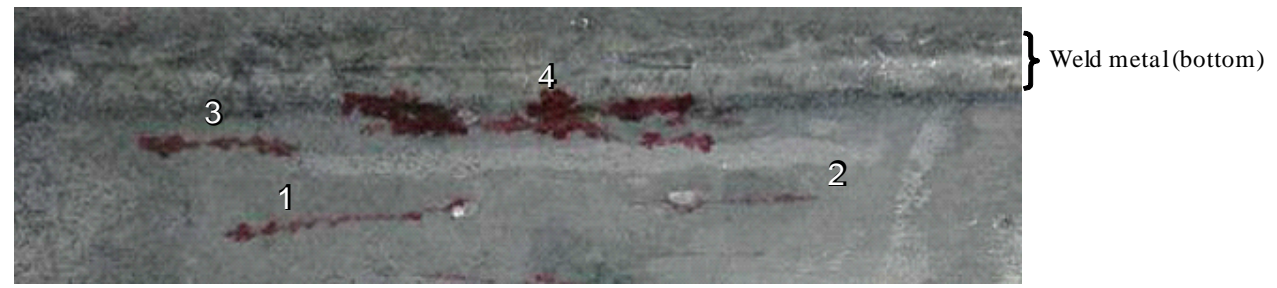

(b) Phased array transducer

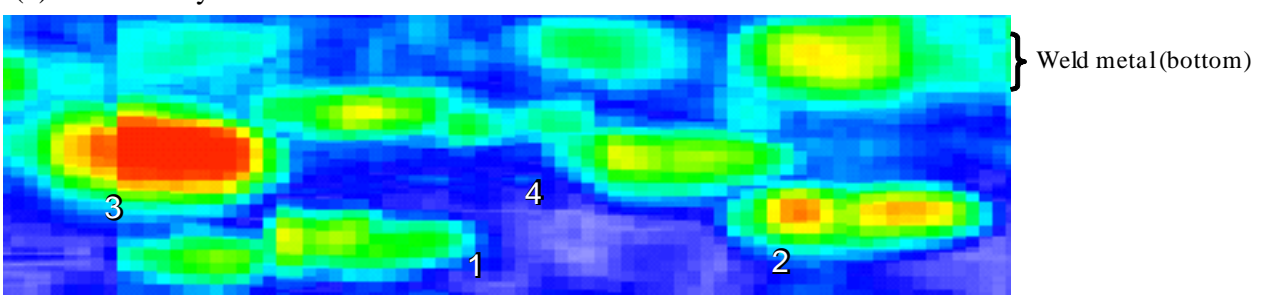

(c) PF-EMAT

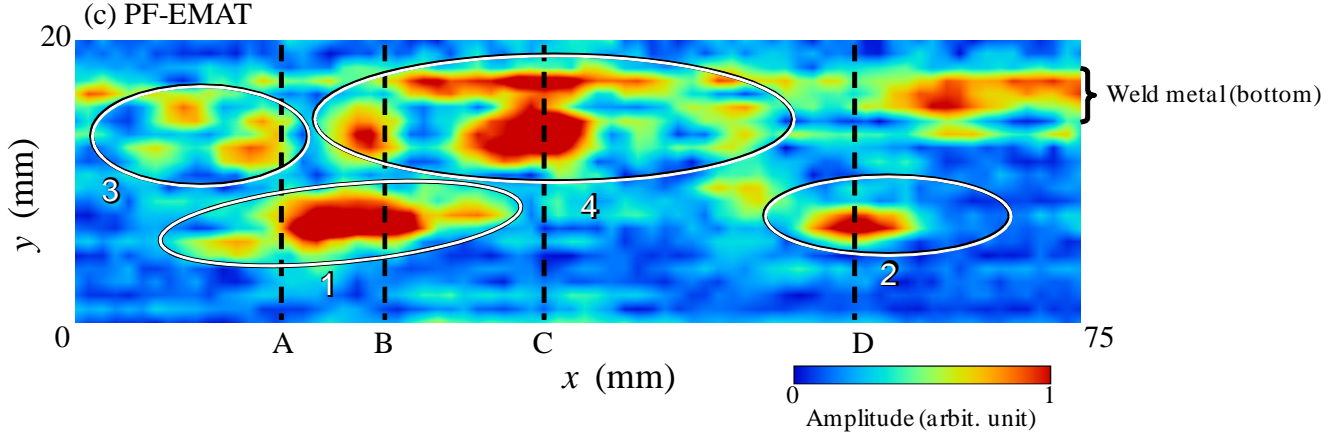

Figure 6: 

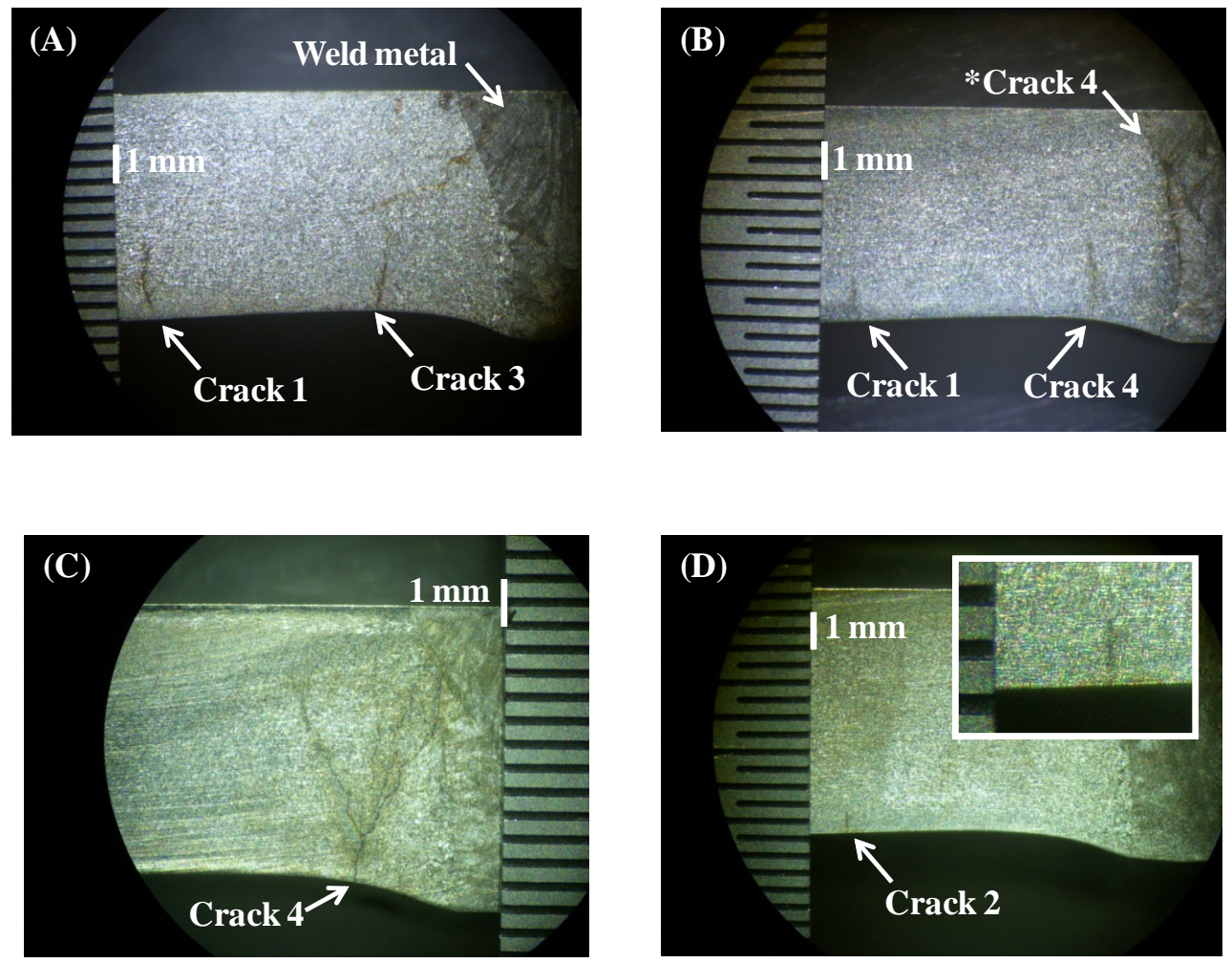

Figure 7: 